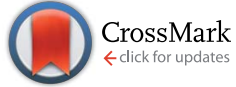

Cite this: RSC Adv., 2017, 7, 16953

Received 23rd January 2017

Accepted 10th March 2017

DOI: $10.1039 / \mathrm{c7ra01006k}$

rsc.li/rsc-advances

\section{Indolylbenzothiadiazoles with varying substituents on the indole ring: a systematic study on the self- recovering mechanochromic luminescence $\dagger$}

\author{
Suguru Ito, * Tomohiro Taguchi, Takeshi Yamada, Takashi Ubukata, \\ Yoshitaka Yamaguchi and Masatoshi Asami
}

\begin{abstract}
Self-recovering mechanochromic luminophores are able to autonomously regain their original color at room temperature after exposure to mechanical stimuli. In spite of recent extensive studies on mechanochromic luminophores, the generation of mechanochromic fluorophores with specific selfrecovering behavior remains a challenging task owing to a lack of systematic studies on self-recovering mechanochromic luminophores. Herein, a series of self-recovering mechanochromic fluorophores with different solid-state emission colors and recovery times is described. The introduction of different substituents onto the indole ring of 4-( $1 \mathrm{H}$-indol-2-yl)-2,1,3-benzothiadiazole afforded control over the mechanochromic luminescence properties of the fluorophores. X-ray diffraction analyses revealed slipped stacks or no intermolecular stacking of the benzothiadiazole rings in the crystalline state of these dyes, which is indicative of the relative lability of the crystal structures upon exposure to mechanical stimuli. Remarkably, the fluorescence spectra after mechanical stimulus (grinding) were in good agreement with those of the molten fluorophores. Based on powder X-ray diffraction and DSC analyses of crystalline and amorphous samples, we propose an amorphization of the crystalline fluorophores to be responsible for the change of emission color in response to mechanical stimuli. Accordingly, the selfrecovering nature should be rationalized in terms of a spontaneous recrystallization of the fluorophores from the amorphous states, which would be facilitated by unchanged partial crystalline phases in the immediate vicinity.
\end{abstract}

\section{Introduction}

Mechanochromic luminescent molecules change their solidstate emission color in response to a mechanical stimulus, and recover their original state by applying a second external stimulus. For this class of dyes, potential applications are conceivable in the context of advanced optical technologies such as pressure sensors, photoswitches, and anticounterfeiting inks. ${ }^{1}$ In recent years, a considerable number of solid-state emissive organic dyes has been developed for optoelectronic applications, whereby the introduction of bulky substituents ${ }^{2}$ and aggregation-induced emission (AIE) ${ }^{3}$ may be used as effective strategies to overcome the concentration quenching caused by the intermolecular interactions of the

Department of Advanced Materials Chemistry, Graduate School of Engineering, Yokohama National University, 79-5 Tokiwadai, Hodogaya-ku, Yokohama 240-8501, Japan.E-mail: suguru-ito@ynu.ac.jp

$\dagger$ Electronic supplementary information (ESI) available: Spectral data, photographs of the solvatochromic luminescence, PXRD data, X-ray diffraction analyses, and theoretical calculations. CCDC 1523441 (1b), 1523442 (1c), 1523443 (1d), 1523444 (1e), 1523445 (1f), 1523446 (1g), and 1523447 (1h). For ESI and crystallographic data in CIF or other electronic format see DOI: 10.1039/c7ra01006k fluorophores in the solid state. Notably, typical AIE-active molecules often also exhibit mechanochromic luminescence. The recent rapid growth in AIE-active molecules, has also led to the development of a growing number of mechanochromic fluorophores based on the structural modifications of typical fluorophores that are emissive in the solid state..$^{4-9}$ However, the practical utility of most mechanochromic fluorophores reported so far suffers from the fact that these systems usually require external stimuli such as heat or exposure to solvents to recover their original color. ${ }^{1,4-9}$ Relatively few are known to recover autonomously at room temperature after exposure to a mechanical stimulus. ${ }^{10}$ In these reports, the structural variation of self-recovering mechanochromic fluorophores is also limited, and only very few compounds in each report exhibited a self-recovering nature. There is a lack of systematic study on the relationship between molecular structures and selfrecovering properties of mechanochromic fluorophores. Recently, we have reported $N$-Boc-4-(3-methyl- $1 H$-indol-2-yl)2,1,3-benzothiadiazole (Boc $=$ tert-butoxycarbonyl) derivatives as a new class of non-AIE-type mechanochromic fluorophores. ${ }^{11}$ The fluorophores exhibited autonomously self-recovering mechanochromic luminescence, and the emission color, as well as the recovery time for the color change could be tuned via 
the substituents on the benzothiadiazole ring. The presence of a methyl group at the 3-position of the indole ring was indispensable to attain mechano-responsive properties, while the presence of the Boc group is important to achieve good fluorescence quantum yields in the solid state. However, the thermal instability of the Boc group hampered the detailed mechanistic study on the self-recovering properties of these fluorophores. Herein, we report the synthesis and emission properties of a series of $N$-substituted-4-(3-alkyl-1H-indol-2-yl)-2,1,3benzothiadiazole derivatives (1). Seven new derivatives, which differ with respect to the substituents at the 3-position and at the $\mathrm{N}$-atom of the indole ring, exhibited self-recovering mechanochromic luminescence properties with varying emission color and recovery time. Detailed studies on molten samples of these mechanochromic fluorophores offered deep insights into the self-recovering mechanochromic luminescence.

\section{Results and discussion}

Following our previously reported procedure for the synthesis of $N$-Boc-indolylbenzothiadiazole $\quad 1 \mathrm{a} \quad\left(\mathrm{R}^{1}=\mathrm{Me}\right){ }^{11} \quad$ 3-alkylsubstituted $\mathbf{1 b}\left(\mathrm{R}^{1}=\mathrm{Et}\right)$ and $\mathbf{1 c}\left(\mathrm{R}^{1}={ }^{\mathrm{i}} \mathrm{Pr}\right)$ were obtained in $48 \%$ and $64 \%$ yield, respectively, from the Suzuki-Miyaura coupling between 4-bromo-2,1,3-benzothiadiazole and the corresponding $N$-Boc-3-alkylindole-2-boronic acid, which was prepared from the respective indole derivatives 2 (Scheme 1). Removal of the Boc group from 1a using trifluoroacetic acid (TFA) in dichloromethane afforded 4-(3-methyl-1 $H$-indol-2-yl)2,1,3-benzothiadiazole (3) in $99 \%$ yield. $N$-Substituted indolylbenzothiadiazole derivatives $\mathbf{1 d}\left(\mathrm{R}^{2}=\right.$ EtOCO), $\mathbf{1 e}\left(\mathrm{R}^{2}=\mathrm{Ts}\right), \mathbf{1 f}$ $\left(\mathrm{R}^{2}=\mathrm{PhCO}\right), \mathbf{1 g}\left(\mathrm{R}^{2}={ }^{t} \mathrm{BuCO}\right)$, and $\mathbf{1 h}\left(\mathrm{R}^{2}=\mathrm{Me}\right)$ were subsequently synthesized in moderate to high yields by a consecutive treatment of 3 with sodium hydride and the corresponding halides $\mathrm{R}^{2} \mathrm{X}(\mathbf{1 d}-\mathrm{g}: \mathrm{X}=\mathrm{Cl}, \mathbf{1 h}: \mathrm{X}=\mathrm{I})$.

The photophysical properties of indolylbenzothiadiazoles $\mathbf{1 a}-\mathbf{h}$ are summarized in Table 1. For 3-alkyl-substituted $\mathbf{1} \mathbf{b}$ and
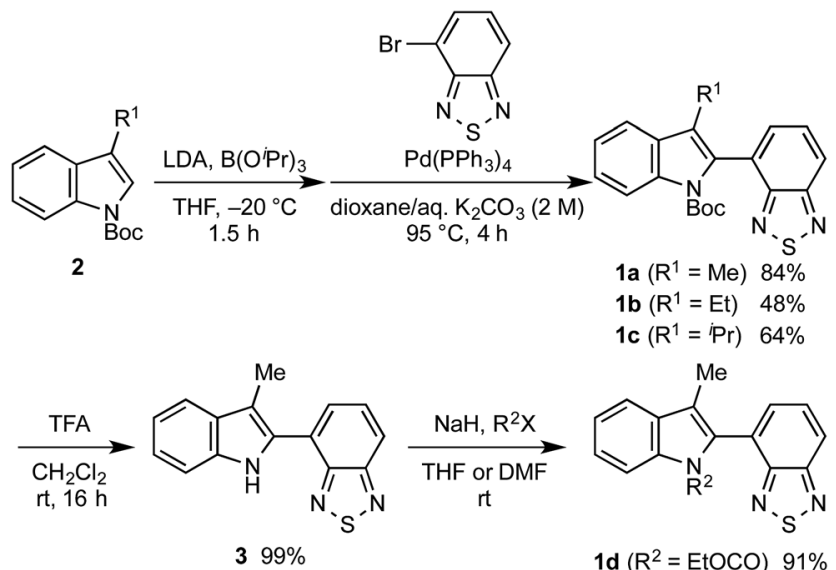

$1 d\left(R^{2}=\right.$ EtOCO) $91 \%$ 1e $\left(R^{2}=T s\right) \quad 72 \%$ 1f $\left(\mathrm{R}^{2}=\mathrm{PhCO}\right) \quad 69 \%$ 1g $\left(R^{2}={ }^{t} \mathrm{BuCO}\right) \quad 66 \%$ 1h $\left(R^{2}=M e\right) \quad 94 \%$

Scheme 1 Synthesis of mechanochromic fluorophores $1 \mathrm{a}-\mathrm{h}$.
Table 1 Photophysical properties of indolylbenzothiadiazoles $1 \mathrm{a}-\mathrm{h}$

\begin{tabular}{|c|c|c|c|c|c|}
\hline \multirow[b]{2}{*}{ Compd. } & \multirow{2}{*}{$\frac{\text { Absorption in toluene }^{a}}{\lambda_{\mathrm{abs}}(\mathrm{nm})}$} & \multicolumn{2}{|c|}{$\begin{array}{l}\text { Fluorescence in } \\
\text { toluene }^{b}\end{array}$} & \multicolumn{2}{|c|}{$\begin{array}{l}\text { Solid-state } \\
\text { fluorescence }^{b}\end{array}$} \\
\hline & & $\lambda_{\mathrm{em}}(\mathrm{nm})$ & $\Phi_{\mathrm{F}}{ }^{c}$ & $\lambda_{\mathrm{em}}(\mathrm{nm})$ & $\Phi_{\mathrm{F}}^{c}$ \\
\hline $1 \mathrm{a}$ & 383 & 523 & 0.43 & 485 & 0.46 \\
\hline $1 b$ & 380 & 521 & 0.36 & 482 & 0.30 \\
\hline $1 \mathrm{c}$ & 380 & 521 & 0.36 & 484 & 0.37 \\
\hline $1 d$ & 380 & 524 & 0.56 & 493 & 0.38 \\
\hline $1 e$ & 371 & 519 & 0.10 & 483 & 0.25 \\
\hline 1f & 391 & 539 & 0.09 & 506 & 0.31 \\
\hline $1 \mathrm{~g}$ & 412 & 560 & 0.08 & 543 & 0.35 \\
\hline $1 \mathrm{~h}$ & 432 & 603 & $0.06^{d}$ & 580 & 0.19 \\
\hline
\end{tabular}

${ }^{a}$ Maximum absorption bands $\left(\lambda_{\mathrm{abs}}>350 \mathrm{~nm}\right)$ in toluene $\left(10^{-5} \mathrm{M}\right)$. ${ }^{b}$ Maximum emission bands $\left(\lambda_{\mathrm{em}}\right)$ and absolute quantum yields $\left(\Phi_{\mathrm{F}}\right)$ in toluene $\left(10^{-5} \mathrm{M}\right)$ and in powdered form. ${ }^{c}$ Absolute quantum yields were measured using an integrating sphere. ${ }^{d}$ As the emission intensity was too weak, $\Phi_{\mathrm{F}}$ was measured by using a $10^{-4} \mathrm{M}$ solution of $\mathbf{1 h}$ in toluene.

1c in toluene, maximum absorption $\left(\lambda_{\text {abs }}\right)$ and emission bands $\left(\lambda_{\mathrm{em}}\right)$ were similar to those of 3-methyl-substituted 1a. The replacement of the Boc group with an ethoxycarbonyl group had a negligible influence on the absorption and emission maxima of $1 \mathbf{d}$ in toluene. The maximum absorption and emission bands of $\mathbf{1 e - h}$ in toluene were bathochromically shifted, whereby the magnitude of the shift increased with a progressive reduction in the electron-withdrawing properties of the substituent on the $\mathrm{N}$ atom of the indole moiety. The fluorescence quantum yields of 1e-h in toluene $\left(\Phi_{\mathrm{F}}=0.06-0.10\right)$ decreased significantly compared to those of the carbamate derivatives $1 \mathbf{a}-\mathbf{d}\left(\Phi_{\mathrm{F}}=\right.$
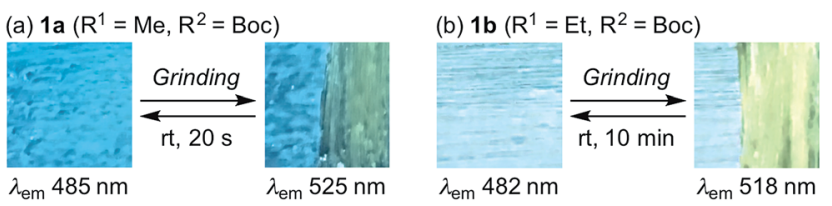

(c) $1 \mathrm{c}\left(\mathrm{R}^{1}={ }^{\mathrm{i}} \mathrm{Pr}, \mathrm{R}^{2}=\mathrm{Boc}\right)$
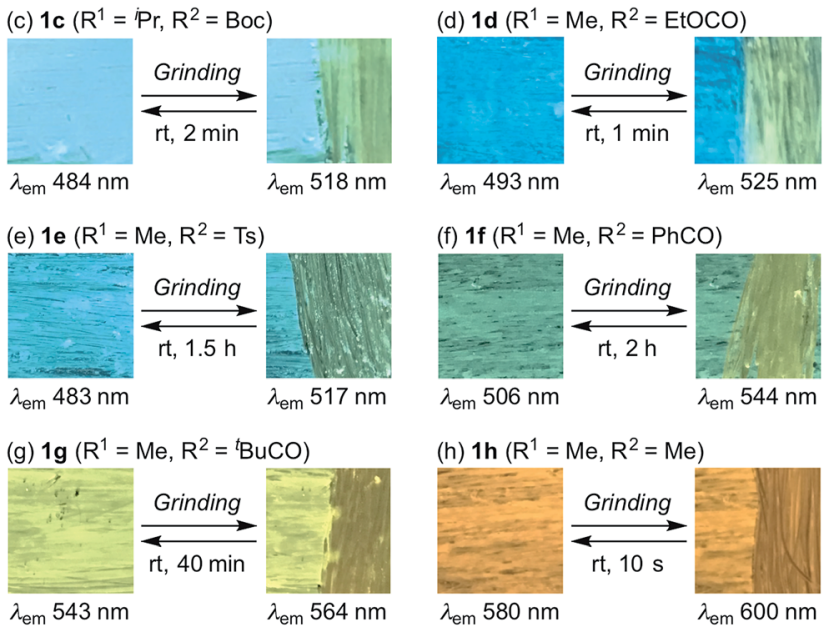

Fig. 1 Photographic images for the autonomously self-recovering mechanochromic luminescence of indolylbenzothiadiazoles $1 a-h$, which differ with respect to the substituents $R^{1}$ and $R^{2}$. 
0.36-0.56). The solid-state emission maximum of powdered $\mathbf{1 b}$ $\left(\lambda_{\mathrm{em}}=482 \mathrm{~nm}, \Phi_{\mathrm{F}}=0.30\right)$ was hypsochromically shifted $\left(\Delta \lambda_{\mathrm{em}}\right.$ $=39 \mathrm{~nm}$ ), while its fluorescence quantum yield was slightly decreased compared to that of a toluene solution $\left(\lambda_{\mathrm{em}}=\right.$ $\left.521 \mathrm{~nm}, \Phi_{\mathrm{F}}=0.36\right)$. Similar to the case of $\mathbf{1 b}$, a large hypsochromic shift $\left(\Delta \lambda_{\mathrm{em}}=37 \mathrm{~nm}\right)$ was observed between the solid-state emission maxima of $1 \mathrm{c}\left(\lambda_{\mathrm{em}}=484 \mathrm{~nm}, \Phi_{\mathrm{F}}=0.37\right)$ and that in toluene $\left(\lambda_{\mathrm{em}}=521 \mathrm{~nm}, \Phi_{\mathrm{F}}=0.36\right)$ under retention of the fluorescence quantum yield. In contrast, the hypsochromic shift of the solid-state emission for 1d $\left(\lambda_{\mathrm{em}}=493\right.$ $\mathrm{nm})$ was relatively moderate $\left(\Delta \lambda_{\mathrm{em}}=31 \mathrm{~nm}\right)$, while the fluorescence quantum yield decreased substantially $\left(\Delta \Phi_{\mathrm{F}}=0.18\right)$. Despite this decrease relative to the solution value, the fluorescence quantum yield for the solid-state emission of $1 \mathbf{d}\left(\Phi_{\mathrm{F}}=\right.$ 0.38) still represents a relatively good value. The emission maxima of 1e-h in the solid state (1e: $483 \mathrm{~nm}$; 1f: $506 \mathrm{~nm}$; 1g: $543 \mathrm{~nm}$; 1h: $580 \mathrm{~nm}$ ) were also hypsochromically shifted relative to those of the corresponding toluene solutions, and the fluorescence quantum yields of $\mathbf{1 e - h}$ afforded satisfactory values (1e: 0.25 , 1f: 0.31 , 1g: 0.35 , 1h: 0.19 ).

With these solid-state emissive fluorophores in hand, we examined their mechano-responsive properties by grinding powdered samples with a spatula (Fig. 1 and S1-7 $\dagger$ ). The maximum emission wavelengths of 3-alkyl-substituted $\mathbf{1 b}$ and 1c were bathochromically shifted to $518 \mathrm{~nm}$ upon grinding, which is almost identical to the value for 1a (Fig. 1a-c). The times required for a recovery of the mechanically changed color was longer for $\mathbf{1 b}(\sim 10 \mathrm{~min})$ than for $\mathbf{1 c}(\sim 2 \mathrm{~min})$ and $1 \mathbf{a}(\sim 20 \mathrm{~s})$. Similarly, the solid-state emission of $N$-ethoxycarbonyl derivative 1d changed to $525 \mathrm{~nm}$ upon grinding, and the original color was recovered within $\sim 1$ min (Fig. 1d). Although the region and magnitude of the mechano-responsive emission shift of 1e were similar to those of $1 \mathrm{a}-\mathbf{d}$, a considerably longer time $(\sim 1.5 \mathrm{~h})$ was required to recover the original color (Fig. 1e). Green-emissive $\mathbf{1 f}$ $\left(\lambda_{\mathrm{em}}=506 \mathrm{~nm}\right)$ and yellow-emissive $1 \mathrm{~g}\left(\lambda_{\mathrm{em}}=543 \mathrm{~nm}\right)$ were by 38 and $21 \mathrm{~nm}$ bathochromically shifted, respectively, in (a) $1 b\left(R^{1}=E t, R^{2}=\right.$ Boc $)$

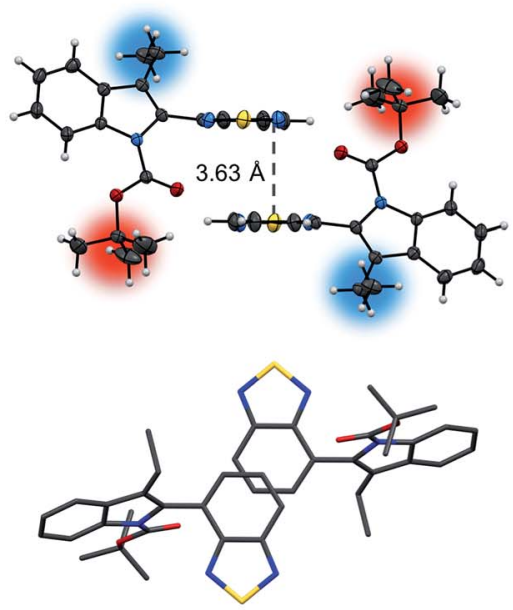

(d) $1 f\left(\mathrm{R}^{1}=\mathrm{Me}, \mathrm{R}^{2}=\mathrm{PhCO}\right)$
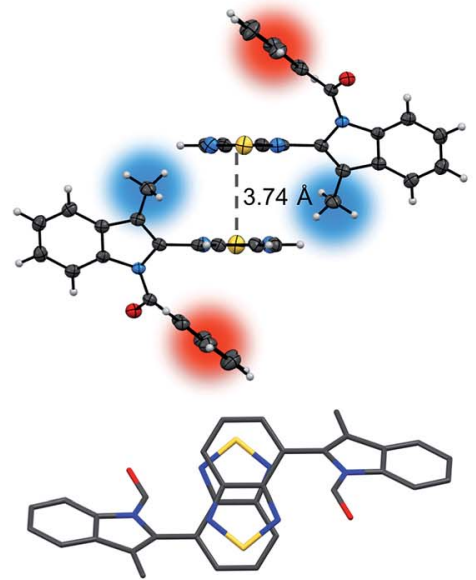

(b) $1 c\left(R^{1}=i \operatorname{Pr}, R^{2}=\right.$ Boc $)$
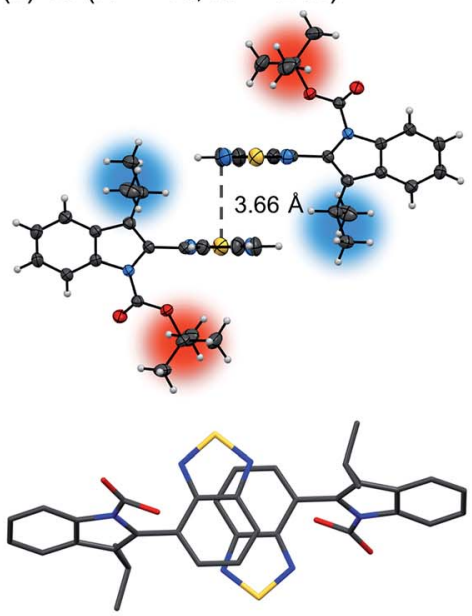

(e) $1 \mathrm{~g}\left(\mathrm{R}^{1}=\mathrm{Me}, \mathrm{R}^{2}={ }^{\mathrm{t}} \mathrm{BuCO}\right)$
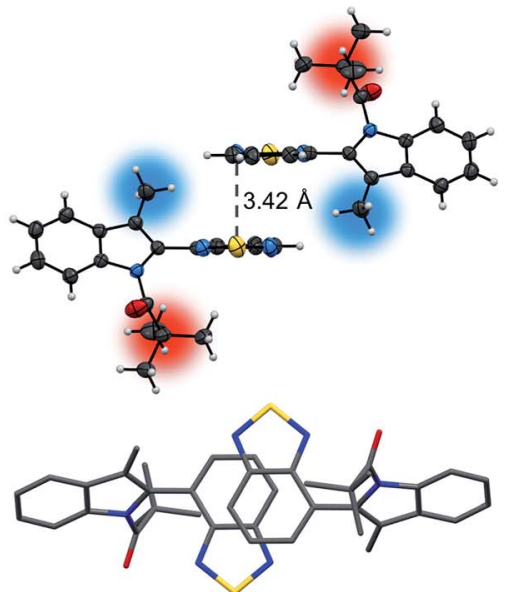

(c) $1 d\left(R^{1}=M e, R^{2}=E t O C O\right)$

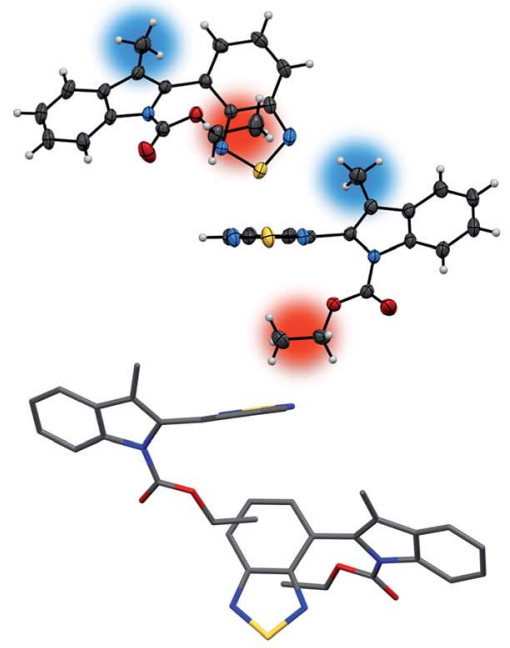

(f) $1 \mathrm{~h}\left(\mathrm{R}^{1}=\mathrm{Me}, \mathrm{R}^{2}=\mathrm{Me}\right)$
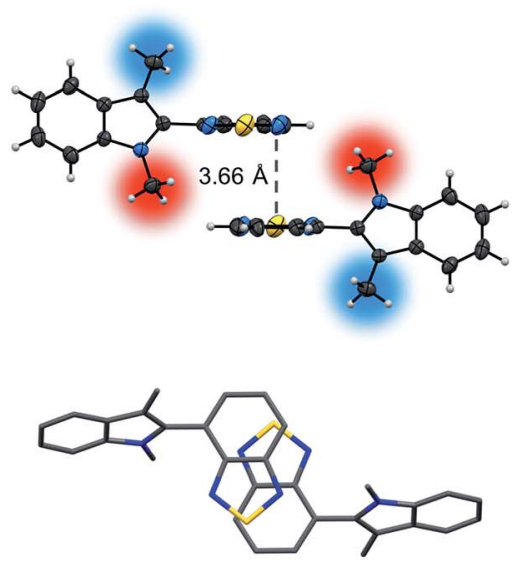

Fig. 2 Molecular structures of $1 \mathrm{~b}(\mathrm{a}), 1 \mathrm{c}(\mathrm{b}), 1 \mathrm{~d}(\mathrm{c}), 1 \mathrm{f}(\mathrm{d}), 1 \mathrm{~g}(\mathrm{e})$, and $1 \mathrm{~h}$ (f). Top rows: front view for two molecules in spatial proximity; atomic displacement parameters set at $30 \%$ (1d and $1 \mathrm{f})$ or $50 \%$ (1b, 1c, $1 \mathrm{~g}$, and $1 \mathrm{~h})$ probability. Bottom rows: top view for two molecules in spatial proximity; all hydrogen atoms and phenyl groups (1f) were omitted for clarity. Color code: gray $=\mathrm{C}$, red $=\mathrm{O}$, blue $=\mathrm{N}$, yellow $=\mathrm{S}$, blurred blue circle $=\mathrm{R}^{1}$, blurred red circle $=\mathrm{R}^{2}$. 
response to mechanical stimuli (Fig. $1 \mathrm{f}$ and $\mathrm{g}$ ). These derivatives also required long recovery times (1f: $\sim 2 \mathrm{~h}$; $1 \mathrm{~g}$ : $\sim 40 \mathrm{~min})$. Upon grinding, the solid-state maximum emission wavelength of $\mathbf{1 h}$ was by $20 \mathrm{~nm}$ bathochromically shifted, while the recovery time of $\mathbf{1 h}(\sim 10 \mathrm{~s})$ was the fastest observed for $\mathbf{1 a}-\mathbf{h}$.

Powder X-ray diffraction (PXRD) analyses for powdered samples of $\mathbf{1 b}-\mathbf{h}$ revealed that these were aggregates of microcrystals. Single-crystal X-ray diffraction analyses of $\mathbf{1 b}-\mathbf{h}$ revealed crystal structures that are identical to those of the powdered samples, except for the case of 1e (Fig. 2 and S8$21 \dagger) .{ }^{12}$ As previously reported, ${ }^{11}$ 1a exhibits anti-parallel intermolecular stacks of benzothiadiazole rings, whereby the tertbutyl groups of the Boc groups are located on the top and bottom of the stacked rings in the crystalline state. Notably, the stacked rings of 1a are offset due to the steric hindrance of the 3methyl groups, which is different to the well-overlapping stacking of the corresponding non-substituted derivative $\left(\mathrm{R}^{1}\right.$ $=\mathrm{H}$ ) (Fig. S22 $\dagger$ ). Of 3-alkyl-substituted $\mathbf{1 b}$ and 1c, the latter exhibited a similar crystal structure to that of 1a (Fig. 2b). This structural similarity should account for the similar photophysical and mechanochromic properties of $\mathbf{1 a}$ and $1 \mathrm{c}$ in the solid state. Conversely, the crystal structure of $\mathbf{1 b}$ is markedly different from that of $\mathbf{1 a}$. The ethoxy group of $\mathbf{1 b}$ is oriented in the opposite direction with respect to the intramolecular benzothiadiazole ring, and only small parts of the benzothiadiazole rings are stacked. As a result, the difference between the recovery times of $1 \mathrm{a}\left(\mathrm{R}^{1}=\mathrm{Me}: \sim 20 \mathrm{~s}\right)$ and $\mathbf{1 b}\left(\mathrm{R}^{1}=\mathrm{Et}: \sim 10 \mathrm{~min}\right)$ is more pronounced than that between $1 \mathrm{a}$ and $\mathbf{1 c}\left(\mathrm{R}^{1}={ }^{\mathrm{i}} \mathrm{Pr}: \sim 2\right.$ $\min$ ), even though the molecular structure of $\mathbf{1 b}$ is closer to that of 1a than that of 1c. The crystal structure of 1d is completely different, due to the exchange of a Boc group with an ethoxycarbonyl group, which resulted in an absence of intermolecular stacking for the benzothiadiazole rings (Fig. 2c). This structural difference between 1d and 1a should help to understand the aforementioned relatively limited hypsochromic shift and partial drop of fluorescence quantum yield for $1 \mathbf{d}$ in the solid state. $N$-Acyl-substituted $\mathbf{1 f}\left(\mathrm{R}^{2}=\right.$ PhCO) and $\mathbf{1 g}\left(\mathrm{R}^{2}=\right.$ $\left.{ }^{t} \mathrm{BuCO}\right)$ also exhibited intermolecular antiparallel stacks of benzothiadiazole rings, wherein two benzene rings or tert-butyl groups of the acyl groups are located on either side of the

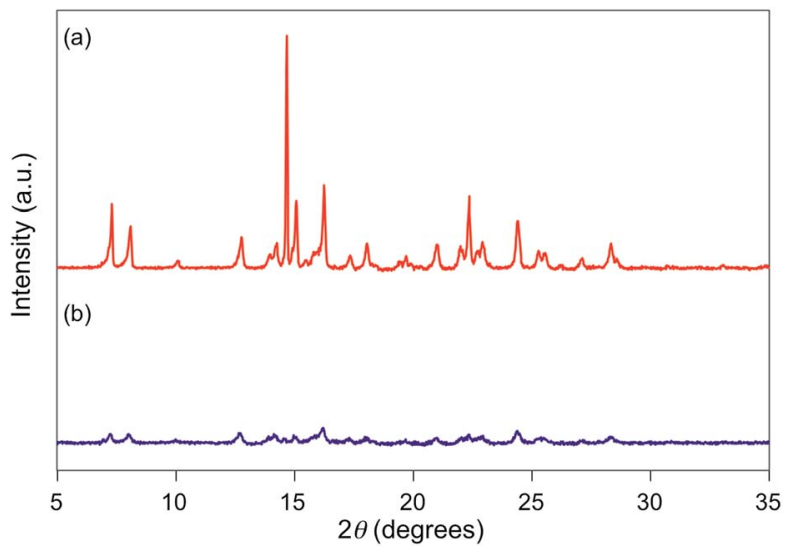

Fig. 3 PXRD patterns for powdered $1 \mathrm{e}$ (a) before and (b) after grinding.

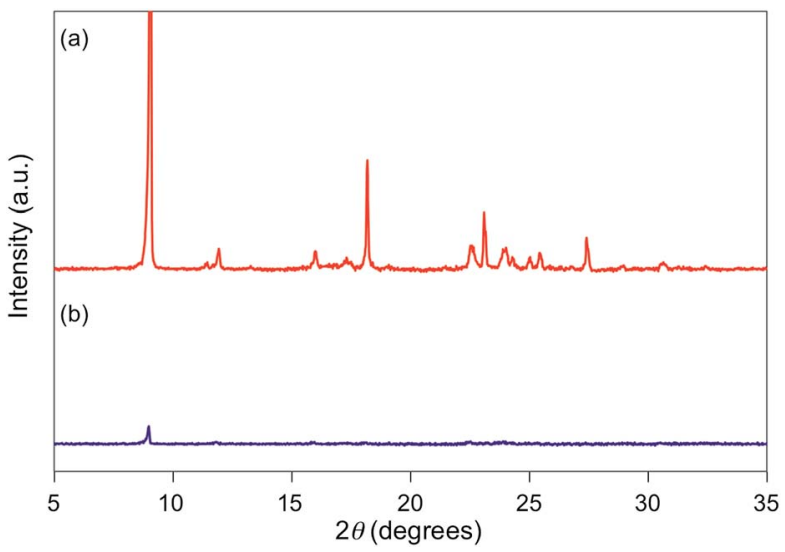

Fig. 4 PXRD patterns for powdered $1 \mathrm{f}(\mathrm{a})$ before and (b) after grinding.

stacked rings (Fig. 2d and e). However, the stacking structures of $1 \mathrm{f}$ and $\mathbf{1 g}$ are different from each other. The sulfur atoms of the benzothiadiazole rings are included in the stacking structure of $\mathbf{1 f}$, whereas those of $\mathbf{1 g}$ protrude from the stacked rings, similar to those of 1a. Intermolecular stacks of $\mathrm{N}$-methylsubstituted $\mathbf{1 h}$ also include the sulfur atoms, and the stacked rings of $\mathbf{1 h}$ share less overlapping area compared to those of $\mathbf{1 f}$ (Fig. 2f). Although antiparallel intermolecular stacking of the benzothiadiazole rings was observed in all cases except for 1d, the stacking modes are different. Nevertheless, all derivatives exhibited mechanochromic luminescence, suggesting that their crystal structures are relatively labile compared to the welloverlapping stacking structures of $\mathrm{N}$-Bocindolylbenzothiadiazoles, which do not contain a substituent at the 3-position $\left(\mathrm{R}^{1}=\mathrm{H}\right)$ and hence not exhibit mechanochromic properties. ${ }^{\mathbf{1 1}}$

For 1e-g, PXRD analyses of the state following the mechanical stimulus were carried out, given that these derivatives exhibited relatively long recovery times. The intensity of the diffraction pattern of 1e significantly decreased after grinding (Fig. 3), indicating that the crystalline powder changed almost completely to an amorphous state. Similarly, crystalline powders of $\mathbf{1 f}$ and $\mathbf{1 g}$ also turned almost completely into

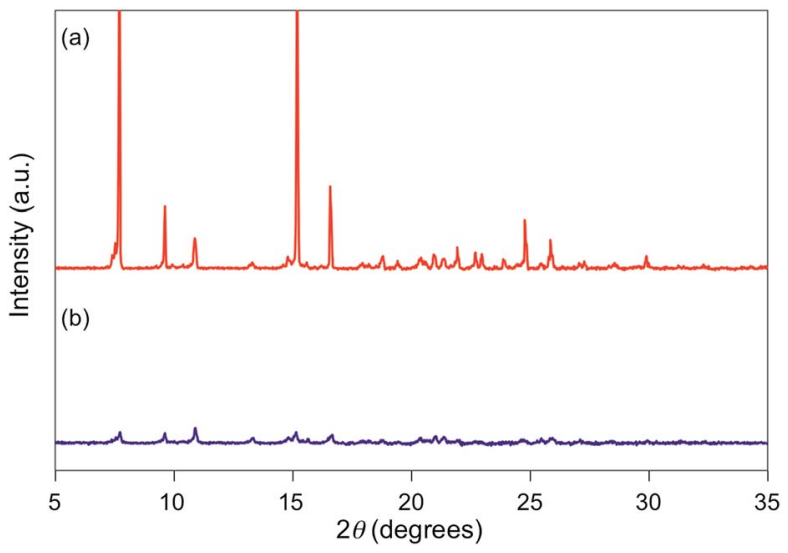

Fig. 5 PXRD patterns for powdered $1 \mathrm{~g}$ (a) before and (b) after grinding. 
(a) $1 \mathbf{b}\left(R^{1}=E t, R^{2}=B o c\right)$

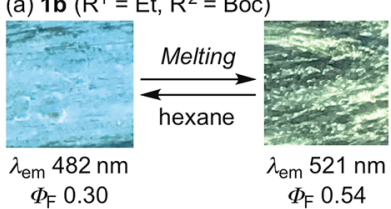

(c) $1 \mathrm{e}\left(\mathrm{R}^{1}=\mathrm{Me}, \mathrm{R}^{2}=\mathrm{Ts}\right)$

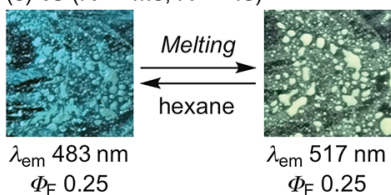

(e) $1 \mathrm{~g}\left(\mathrm{R}^{1}=\mathrm{Me}, \mathrm{R}^{2}={ }_{\mathrm{B}}^{\mathrm{B} u C O}\right)$

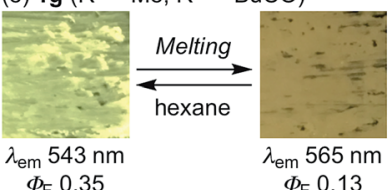

(b) $1 d\left(R^{1}=M e, R^{2}=\right.$ EtOCO)

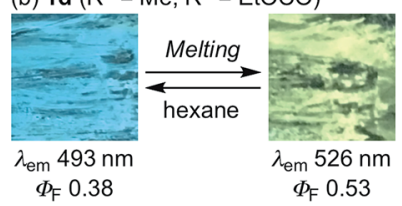

(d) $1 f\left(R^{1}=\mathrm{Me}, \mathrm{R}^{2}=\mathrm{PhCO}\right)$

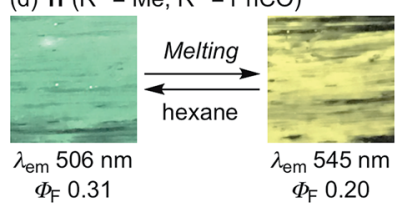

(f) $1 \mathrm{~h}\left(\mathrm{R}^{1}=\mathrm{Me}, \mathrm{R}^{2}=\mathrm{Me}\right)$

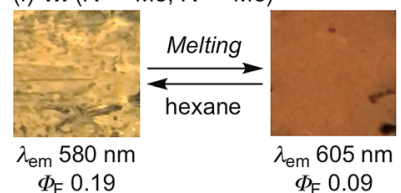

Fig. 6 Photographic images for the luminescence of molten samples of indolylbenzothiadiazoles $1 \mathrm{~b}$ and $1 \mathrm{~d}-\mathrm{h}$.

amorphous states in response to the mechanical stimulus (Fig. 4 and 5). These results suggest that the mechanoresponsive emission color change of these fluorophores is triggered by an amorphization of the crystals.

An optimization of the molecular structures of $\mathbf{1 b}-\mathbf{h}$ was carried out by density functional theory (DFT) calculations at the CAM-B3LYP/6-31G(d) level of theory, ${ }^{13}$ using the single-crystal Xray diffraction structures as the initial geometry. In all cases, the HOMO is mainly localized on the indole ring and on a part of the benzothiadiazole moiety, whereas the LUMO is localized on the benzothiadiazole ring (Fig. S23†). Time-dependent DFT calculations on the optimized structures of $\mathbf{1} \mathbf{b}-\mathbf{h}$ revealed that the maximum-wavelength absorption bands should be assigned to the HOMO $\rightarrow$ LUMO transition (Table S1 and Fig. S24 $\dagger$ ). Such an intramolecular charge-transfer transition would explain the large Stokes shifts and solvatochromic luminescence observed for $\mathbf{1 b}$ h (Fig. S25-31†). Solvatochromic luminescence is usually caused by an efficient stabilization of excited states in polar solvents. ${ }^{\mathbf{1 4}}$ The potentially solvatofluorochromic nature of $\mathbf{1} \mathbf{b}-\mathbf{h}$ might be one reason for their change of emission color by amorphization, as the polarity surrounding the fluorophores should be different in the crystalline and amorphous state.

Fluorescence spectra of the molten mechanochromic fluorophores were measured to examine the change of emission color upon losing crystallinity. Although thermal annealing is a widely applied method to recover the original emission color after exposure to mechanical stimuli, there is a lack of systematic study on the relationship between the emission color of the molten and mechanically changed states. ${ }^{10 f, 15,16} \mathrm{~N}$-Boc derivatives 1a and 1c decomposed upon heating prior to reaching their melting points, most likely due to the thermal instability of the Boc group. Derivatives $\mathbf{1 b}$ and $\mathbf{1 d - h}$ liquefied at temperatures above their melting points, ${ }^{17}$ and the fluorescence spectra were recorded after cooling the samples rapidly to room temperature. In all cases, bathochromic shifts of the emission maxima were observed upon melting (Fig. 6). Notably, the

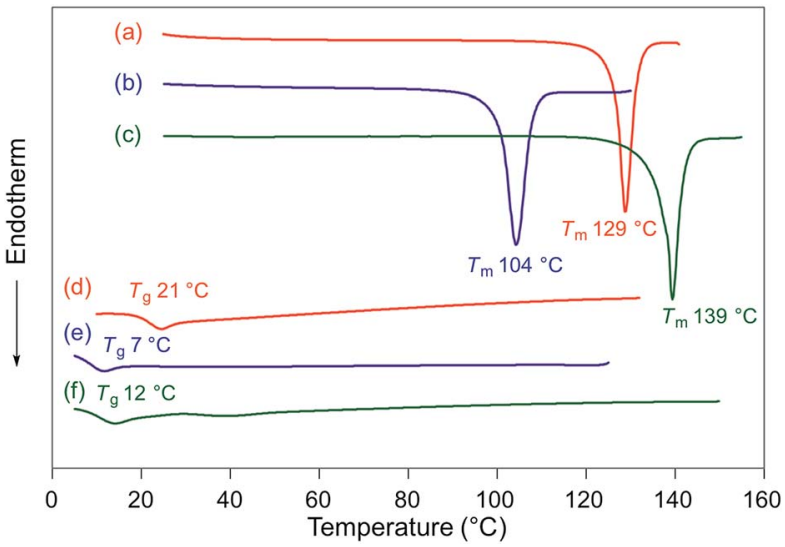

Fig. 7 DSC thermograms for powdered and molten samples of $1 \mathrm{~b}$ (a and d), $1 \mathrm{~d}$ ( $\mathrm{b}$ and e), and $1 \mathrm{~g}$ (c and f). $T_{\mathrm{m}}$ and $T_{\mathrm{g}}$ values are noted near the corresponding peaks and steps.

fluorescence spectra of the molten samples were in good agreement with those of the mechanically changed states (Fig. S1 and $3-7 \dagger$ ). Differential scanning calorimetry (DSC) measurements were carried out on powdered and molten samples of $\mathbf{1 b}$ and $\mathbf{1 d - h}$ (Fig. 7 and 8). The DSC thermograms of all powdered crystalline samples showed only one endothermic peak that corresponds to their melting points, while transition peaks to another crystalline phase were not observed prior to melting. For the molten samples, glass-transition temperatures $\left(T_{\mathrm{g}}\right)$ were observed for $\mathbf{1 b}\left(21^{\circ} \mathrm{C}\right)$, $1 \mathrm{~d}\left(7^{\circ} \mathrm{C}\right)$, and $1 \mathrm{~g}\left(12^{\circ} \mathrm{C}\right)$, which exhibit lower melting points $\left(T_{\mathrm{m}} ; \mathbf{1 b}: 129{ }^{\circ} \mathrm{C}, \mathbf{1 d}: 104{ }^{\circ} \mathrm{C}, \mathbf{1 g}: 139\right.$ ${ }^{\circ} \mathrm{C}$ ), whereas $T_{\text {g }}\left(\mathbf{1 e}: 45{ }^{\circ} \mathrm{C}\right.$, 1f: $\left.39{ }^{\circ} \mathrm{C}, \mathbf{1 h}: 16{ }^{\circ} \mathrm{C}\right)$ and coldcrystallization transition temperatures were observed for $\mathbf{1 e}$, 1f, and $1 \mathrm{~h}\left(T_{\mathrm{c}}\right.$; 1e: $125{ }^{\circ} \mathrm{C}$, 1f: $106{ }^{\circ} \mathrm{C}$, 1h: $\left.80{ }^{\circ} \mathrm{C}\right)$, which exhibit higher $T_{\mathrm{m}}$ values $\left(\mathbf{1 e :} 183{ }^{\circ} \mathrm{C}\right.$, 1f: $194{ }^{\circ} \mathrm{C}$, 1h: $\left.145{ }^{\circ} \mathrm{C}\right)$. These results support the notion that mechanical stimuli cause a transition of the powdered crystalline state to a glass or supercooled liquid state with different emission properties. The relatively long recovery times for $\mathbf{1 e}$ and $\mathbf{1 f}$ might be explained as these are in glass states at room temperature.

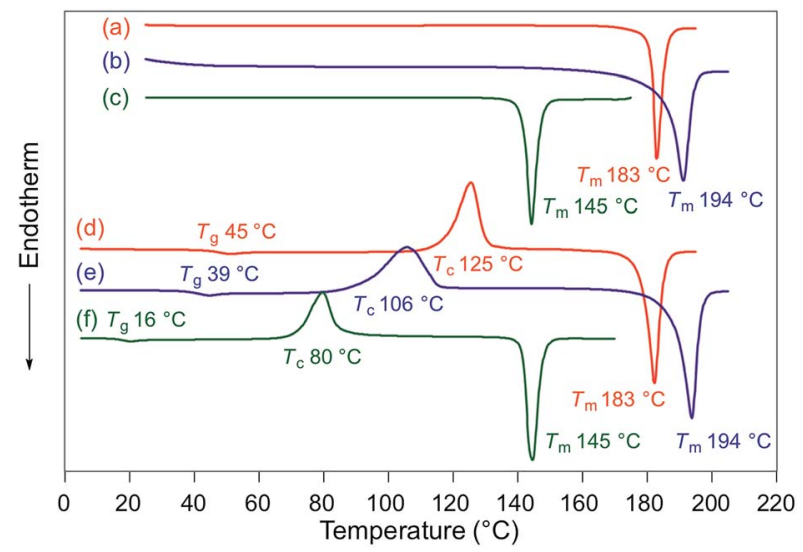

Fig. 8 DSC thermograms for powdered and molten samples of 1e (a and d), $1 \mathrm{f}$ ( $\mathrm{b}$ and e), and $1 \mathrm{~h}$ (c and f). $T_{\mathrm{m}}, T_{\mathrm{c}}$, and $T_{\mathrm{g}}$ values are noted near the corresponding peaks and steps. 
The molten samples required considerably longer times (several hours to several days) to recover the original emission color at room temperature. Meanwhile, the original emission color was immediately recovered upon scratching hexane suspensions of molten samples with a spatula followed by natural evaporation (Fig. 6). The stability of the molten amorphous samples should be explained by the complete loss of crystallinity, in contrast to the amorphous state created by mechanical stimuli. The recrystallization of the mechanically created amorphous phases should be facilitated by the presence of unchanged crystalline phases in close spatial proximity, which should lead to a fast recovery of the emission color at room temperature. The difference in recovery time would be associated with the degree of crystallinity of the crystal structure, or the stabilization of the amorphous phase by polarized substituents.

\section{Conclusion}

A series of self-recovering mechanochromic fluorophores was obtained by introducing different substituents on the indole ring of indolylbenzothiadiazole. Although the mechanochromic luminescence for 1a-e was observed in the blue to green region irrespective of their structural differences, the times required for the recovery of the original color varied from $20 \mathrm{~s}$ to $1.5 \mathrm{~h}$. For 1f-h, which contain benzoyl, pivaloyl, or methyl groups at $\mathrm{N}$-atom of the indole ring, respectively, bathochromically shifted solid-state emission colors relative to 1a-e were observed. The recovery time increased upon introduction of acyl groups, and shortened by the presence of the $N$-methyl group. All these mechanochromic fluorophores are crystalline powders, and the PXRD analyses for 1e-g, which exhibit relatively long recovery times, indicated a loss of crystallinity in response to mechanical stimuli. Moreover, the fluorescence spectra of samples of $\mathbf{1 b}$ and 1d-h after grinding showed good agreement with those for the molten amorphous state, whereas a considerably longer time was required for the molten samples to recover their crystallinity at room temperature. The DSC analyses for the molten samples exhibited that the $T_{\mathrm{g}}$ values for $\mathbf{1 e}$ and $\mathbf{1 f}$ are above room temperature, which might explain the long recovery times of these fluorophores. These results suggest that the present mechanism of self-recovering mechanochromic luminescence is based on an amorphization of the crystals upon grinding, followed by spontaneous recrystallization of the amorphous phase, which should be facilitated by the presence of unchanged crystalline phases in the immediate vicinity. Self-recovering mechanochromic fluorophores should potentially find applications in mechano-sensors that may provide information on the timelapse after exposure to a mechanical stimulus or in anticounterfeiting inks that may temporarily change their emission color upon crumpling. The present study should offer guidelines to further the development of such smart materials.

\section{Experimental}

\section{General}

All air-sensitive experiments were carried out under an atmosphere of argon unless otherwise noted. IR spectra were recorded on a Nicolet iS10 FT-IR spectrometer. ${ }^{1} \mathrm{H}$ and ${ }^{13} \mathrm{C}$ NMR spectra were recorded on a Bruker DRX-300 or DRX-500 spectrometer using tetramethylsilane as an internal standard. UV-vis absorption and fluorescence spectra were measured on a JASCO V560 spectrophotometer and a JASCO FP-8300 or FP-8500 fluorescence spectrometer, respectively. The absolute fluorescence quantum yields were determined using a $100 \mathrm{~mm} \phi$ integrating sphere JASCO ILF-835. A miniature fiber-optic spectrometer (FLAME-S-XR1-ES, Ocean Optics) was used for the measurements of mechanochromic luminescence. PXRD measurements were performed on a Rigaku RINT-2500 system using CuK $\alpha$ radiation. Melting points were determined on a Stuart melting point apparatus SMP3 and are uncorrected. DSC data were recorded on a Seiko Instruments DSC-6100 equipped with a liquid nitrogen cooling unit (heating rate: $10{ }^{\circ} \mathrm{C} \mathrm{min}^{-1}$ ). High-resolution mass spectra (HRMS) were recorded on a JEOL JMS-600 mass spectrometer (EI) and a Hitachi Nano Frontier LD spectrometer (ESI). Elemental analyses were carried out on a Vario EL III Elemental analyzer. TLC analyses were done on silica-gel $60 \mathrm{~F}_{254}$-precoated aluminum backed sheets (E. Merck). Wakogel C-200 and Silica gel $60 \mathrm{~N}$ (spherical, neutral, 63-210 $\mu \mathrm{m}$ ) were used for column chromatography. $\quad \mathrm{N}$-Boc-3-methyl-1H-indole $(\mathbf{2 a}){ }^{18} \mathrm{~N}$-Boc-3-ethyl-1 $H$ indole (2b) ${ }^{19}$ 3-isopropyl-1 $H$-indole, ${ }^{20}$ 4-bromo-2,1,3-benzothiadiazole, $^{21}$ and tert-butyl 2-(2,1,3-benzothiadiazol-4-yl)-3-methyl-1 $H^{-}$ indole-1-carboxylate (1a) ${ }^{\mathbf{1 1}}$ were synthesized according to the literature procedure. The spectroscopic grade solvents for UV-vis absorption and fluorescence measurements were purchased from Kanto Chemical Co., Inc. and Wako Pure Chemical Industries, Ltd.

\section{Synthesis of $\mathrm{N}$-Boc-3-isopropyl-1H-indole (2c)}

To a stirred solution of 3-isopropyl- $1 H$-indole $(480 \mathrm{mg}, 3.0 \mathrm{mmol})$ and DMAP (37 mg, $0.30 \mathrm{mmol}$ ) in dichloromethane $(30 \mathrm{~mL})$ was added di-tert-butyl dicarbonate $(790 \mathrm{mg}, 3.6 \mathrm{mmol})$, and the mixture was stirred at room temperature for $24 \mathrm{~h}$. After water was added to the mixture, the organic layer was separated and the aqueous layer was extracted with dichloromethane three times. The combined organic layer was washed with water and brine, and dried over anhydrous $\mathrm{Na}_{2} \mathrm{SO}_{4}$. After removal of the solvent under reduced pressure, crude product was purified with silica-gel column chromatography (hexane/ethyl acetate $=30: 1$ ) to give $N$ Boc-3-isopropyl-1H-indole (2c, $765 \mathrm{mg}, 98 \%$ ) as colorless oil.

$\boldsymbol{N}$-Boc-3-isopropyl-1H-indole (2c). Colorless oil; IR (neat): $\nu_{\max }$ 3051, 2966, 2931, 2872, 2391, 2360, 1732, 1609, 1568, 1455, 1422, 1371, 1340, 1309, 1298, 1255, 1221, 1158, 1108, 1085, 1064, 1021, 1000, 935, 858, 835, 804, 765, 745, $668 \mathrm{~cm}^{-1} ;{ }^{1} \mathrm{H}$ NMR $(500 \mathrm{MHz}$, $\left.\mathrm{CDCl}_{3}\right): \delta(\mathrm{ppm}) 8.13$ (br s, $\left.1 \mathrm{H}\right), 7.55(\mathrm{~d}, J=7.9 \mathrm{~Hz}, 1 \mathrm{H}), 7.33(\mathrm{br} \mathrm{s}$, 1H), 7.31-7.27 (m, 1H), 7.24-7.19 (m, 1H), 3.12-3.09 (m, 1H), 1.65 (s, 9H), 1.34 (d, $J=6.6 \mathrm{~Hz}, 6 \mathrm{H}) ;{ }^{13} \mathrm{C} \mathrm{NMR} \mathrm{(126} \mathrm{MHz,} \mathrm{CDCl}_{3}$ ): $\delta$ (ppm) 149.9, 135.7, 130.1, 128.0, 124.1, 122.1, 120.5, 119.3, 115.3, 83.2, 28.2, 25.2, 22.6; anal. calcd for $\mathrm{C}_{16} \mathrm{H}_{21} \mathrm{NO}_{2}$ : C, 74.10; H, 8.16; N, 5.40. Found: C, 73.72; H, 8.32; N, 5.45.

\section{Synthesis of $N$-Boc-indolylbenzothiadiazole derivatives $1 \mathrm{~b}$ and} 1c

Typical experimental procedure (1b, Scheme 1). To a stirred solution of $\mathrm{N}$-Boc-3-ethylindole $(245 \mathrm{mg}, 1.0 \mathrm{mmol})$ and 
triisopropyl borate $(282 \mathrm{mg}, 1.5 \mathrm{mmol})$ in THF $(4.0 \mathrm{~mL})$ was added a solution of lithium diisopropyl amide, prepared from diisopropylamine $(350 \mu \mathrm{L}, 2.5 \mathrm{mmol})$ and butyllithium $(2.6 \mathrm{M}$ in hexane, $960 \mu \mathrm{L}, 2.5 \mathrm{mmol})$ in THF $(2.0 \mathrm{~mL})$, through a syringe at $-20{ }^{\circ} \mathrm{C}$, and the mixture was stirred at the same temperature for $1.5 \mathrm{~h}$. Saturated ammonium chloride solution and water were added to the reaction mixture. The organic layer was separated and the aqueous layer was extracted with ethyl acetate three times. The combined organic layer was washed with water and brine, and dried over anhydrous $\mathrm{Na}_{2} \mathrm{SO}_{4}$. After removal of the solvent under reduced pressure, crude product was dissolved in dioxane $(6.0 \mathrm{~mL})$. To the solution was added 4-bromo-2,1,3benzothiadiazole $(129 \mathrm{mg}, 0.6 \mathrm{mmol})$ and $2 \mathrm{M}$ aqueous $\mathrm{K}_{2} \mathrm{CO}_{3}$ $(0.6 \mathrm{~mL})$, and the mixture was degassed under ultrasonic irradiation. To the mixture was added $\mathrm{Pd}\left(\mathrm{PPh}_{3}\right)_{4}(139 \mathrm{mg}, 0.12$ $\mathrm{mmol})$, and the mixture was further degassed under ultrasonic irradiation. After the mixture was stirred at $95{ }^{\circ} \mathrm{C}$ for $4 \mathrm{~h}$, water and dichloromethane were added to the mixture. The organic layer was separated and the aqueous layer was extracted with dichloromethane three times. The combined organic layer was washed with water and brine, and dried over anhydrous $\mathrm{Na}_{2} \mathrm{SO}_{4}$. After removal of the solvent under reduced pressure, crude product was purified with silica-gel column chromatography (hexane/diethyl ether $=10: 1$ ) to give tert-butyl-2-(2,1,3-benzothiadiazol-4-yl)-3-ethyl-1 $H$-indole-1-carboxylate (1b, 109 mg, $48 \%)$ as yellow solid.

tert-Butyl 2-(2,1,3-benzothiadiazol-4-yl)-3-ethyl-1 $\mathrm{H}$-indole-1carboxylate (1b). Yellow solid; mp 128.0-128.6 ${ }^{\circ} \mathrm{C}$; IR (KBr): $\nu_{\max } 2969,1732,1601,1538,1454,1411,1392,1369,1332,1286$, 1254, 1223, 1149, 1116, 1089, 1018, 905, 878, 846, 815, 796, 763, 743, $705 \mathrm{~cm}^{-1} ;{ }^{1} \mathrm{H}$ NMR $\left(500 \mathrm{MHz}, \mathrm{CDCl}_{3}\right): \delta(\mathrm{ppm}) 8.31(\mathrm{dt}, J=$ 8.3, $0.9 \mathrm{~Hz}, 1 \mathrm{H}), 8.04(\mathrm{dd}, J=8.8,1.1 \mathrm{~Hz}, 1 \mathrm{H}), 7.69(\mathrm{dd}, J=8.8$, $6.8 \mathrm{~Hz}, 1 \mathrm{H}), 7.63(\mathrm{ddd}, J=7.2,1.3,0.9 \mathrm{~Hz}, 1 \mathrm{H}), 7.56(\mathrm{dd}, J=6.8$, $1.1 \mathrm{~Hz}, 1 \mathrm{H}), 7.39$ (ddd, $J=8.3,7.2,1.3 \mathrm{~Hz}, 1 \mathrm{H}), 7.30(\mathrm{td}, J=7.2$, $0.9 \mathrm{~Hz}, 1 \mathrm{H}), 2.68(\mathrm{dt}, J=21.8,7.6 \mathrm{~Hz}, 1 \mathrm{H}), 2.53(\mathrm{dt}, J=21.8$, $7.6 \mathrm{~Hz}, 1 \mathrm{H}), 1.20(\mathrm{t}, J=7.6 \mathrm{~Hz}, 3 \mathrm{H}), 0.97(\mathrm{~s}, 9 \mathrm{H}) ;{ }^{13} \mathrm{C}$ NMR $(126$ $\left.\mathrm{MHz}, \mathrm{CDCl}_{3}\right): \delta(\mathrm{ppm})$ 155.0, 154.9, 149.9, 136.9, 130.3, 129.3, 128.7, 128.3, 125.0, 124.3, 122.6, 121.0, 119.2, 115.7, 82.4, 27.4, 17.8, 15.3; anal. calcd for $\mathrm{C}_{21} \mathrm{H}_{21} \mathrm{~N}_{3} \mathrm{O}_{2} \mathrm{~S}$ : C, 66.47; H, 5.58; N, 11.07; S, 8.45. Found: C, 66.20; H, 5.76; N, 10.88; S, 8.40. Crystal data for $1 \mathrm{~b}$ (CCDC 1523441†): $\mathrm{C}_{21} \mathrm{H}_{21} \mathrm{~N}_{3} \mathrm{O}_{2} \mathrm{~S}, M=379.48$, triclinic, $a=9.401(5) \AA, b=10.660(5) \AA, c=11.058(5) \AA, \alpha=$ 107.936(5) ${ }^{\circ}, \beta=98.134(3)^{\circ}, \gamma=110.380(3)^{\circ}, V=949.1(8) \AA^{3}$, space group $P \overline{1}$ (no. 2), $Z=2, D_{\mathrm{c}}=1.328 \mathrm{~g} \mathrm{~cm}^{-3}, F(000)=$ $400.00, T=223(1) \mathrm{K}, \mu(\mathrm{Mo}-\mathrm{K} \alpha)=1.917 \mathrm{~cm}^{-1}$, 6870 reflections measured, 4148 independent $\left(R_{\mathrm{int}}=0.0206\right)$. The final refinement converged to $R_{1}=0.0463$ for $I>2.0 \sigma(I), \mathrm{w} R_{2}=0.1320$ for all data.

tert-Butyl 2-(2,1,3-benzothiadiazol-4-yl)-3-isopropyl-1H-indole1-carboxylate (1c). Yellow solid; $\mathrm{mp}>145^{\circ} \mathrm{C}$ decomp.; IR (KBr): $\nu_{\max } 3075,3015,2973,2931,2873,1721,1600,1536,1456,1417$, 1366, 1331, 1274, 1236, 1210, 1157, 1110, 1087, 999, 903, 868, 851, 818, 811, 769, $754 \mathrm{~cm}^{-1} ;{ }^{1} \mathrm{H}$ NMR (500 MHz, $\left.\mathrm{CDCl}_{3}\right): \delta(\mathrm{ppm}) 8.34$ $(\mathrm{dt}, J=8.3,1.0 \mathrm{~Hz}, 1 \mathrm{H}), 8.05(\mathrm{dd}, J=8.8,1.0 \mathrm{~Hz}, 1 \mathrm{H}), 7.80$ (ddd, $J$ $=7.9,1.3,1.0 \mathrm{~Hz}, 1 \mathrm{H}), 7.69(\mathrm{dd}, J=8.8,6.7 \mathrm{~Hz}, 1 \mathrm{H}), 7.52(\mathrm{dd}, J=$ 6.7, $1.0 \mathrm{~Hz}, 1 \mathrm{H}$ ), 7.37 (ddd, $J=8.3,7.3,1.3 \mathrm{~Hz}, 1 \mathrm{H}), 7.27$ (ddd, $J=$ 7.9, 7.3, 1.0 Hz, 1H), 2.93 (sept, $J=7.3 \mathrm{~Hz}, 1 \mathrm{H}), 1.42$ (d, $J=7.3 \mathrm{~Hz}$,
$3 \mathrm{H}), 1.26(\mathrm{~d}, J=7.3 \mathrm{~Hz}, 3 \mathrm{H}), 0.95(\mathrm{~s}, 9 \mathrm{H}) ;{ }^{13} \mathrm{C}$ NMR $(126 \mathrm{MHz}$, $\left.\mathrm{CDCl}_{3}\right): \delta$ (ppm) 155.1, 154.9, 149.8, 137.2, 129.3, 129.24, 129.20, 128.6, 128.0, 127.7, 124.6, 122.2, 121.1, 120.8, 115.8, 82.4, 27.4, 26.3, 22.6, 22.3; anal. calcd for $\mathrm{C}_{22} \mathrm{H}_{23} \mathrm{~N}_{3} \mathrm{O}_{2} \mathrm{~S}: \mathrm{C}, 67.15 ; \mathrm{H}, 5.89 ; \mathrm{N}$, 10.68; S, 8.15. Found: C, 66.75; H, 5.93; N, 10.66; S, 8.32. Crystal data for 1c (CCDC 1523442 $\dagger$ ): $\mathrm{C}_{22} \mathrm{H}_{23} \mathrm{~N}_{3} \mathrm{O}_{2} \mathrm{~S}, M=393.50$, triclinic, $a=9.38360 \AA, b=9.5084(5) \AA, c=12.6685(3) \AA, \alpha=84.707(12)^{\circ}$, $\beta=69.198(7)^{\circ}, \gamma=77.736(12)^{\circ}, V=1032.35(9) \AA^{3}$, space group $P \overline{1}$ (no. 2) $Z=2, D_{\mathrm{c}}=1.266 \mathrm{~g} \mathrm{~cm}^{-3}, F(000)=416.00, T=223(1) \mathrm{K}$, $\mu(\mathrm{Mo}-\mathrm{K} \alpha)=1.787 \mathrm{~cm}^{-1}, 7509$ reflections measured, 4499 independent $\left(R_{\mathrm{int}}=0.0196\right)$. The final refinement converged to $R_{1}=$ 0.0455 for $I>2.0 \sigma(I), \mathrm{w} R_{2}=0.1229$ for all data.

\section{Synthesis of 4-(3-methyl-1H-indol-2-yl)-2,1,3-benzothiadiazole} (3)

To a stirred solution of $1 \mathrm{a}(219 \mathrm{mg}, 0.6 \mathrm{mmol})$ in dichloromethane $(9.8 \mathrm{~mL})$ was added trifluoroacetic acid $(2.2 \mathrm{~mL})$ at $0{ }^{\circ} \mathrm{C}$, and the mixture was stirred at room temperature for $16 \mathrm{~h}$. After the mixture was cooled to $0{ }^{\circ} \mathrm{C}$, saturated aqueous sodium hydrogen carbonate solution was added to the mixture. The organic layer was separated and the aqueous layer was extracted with dichloromethane three times. The combined organic layer was washed with water and brine, and dried over anhydrous $\mathrm{Na}_{2} \mathrm{SO}_{4}$. After removal of the solvent under reduced pressure, crude product was purified with silica-gel column chromatography (hexane/diethyl ether $=1: 1$ ) to give 4-(3-methyl-1Hindol-2-yl)-2,1,3-benzothiadiazole $(3,157 \mathrm{mg}, 99 \%)$ as redorange solid.

4-(3-Methyl-1H-indol-2-yl)-2,1,3-benzothiadiazole (3). Redorange solid; mp $123-124{ }^{\circ} \mathrm{C}$; IR (KBr): $\nu_{\max } 3482$, 3381, 3054, 2963, 2861, 1645, 1588, 1541, 1523, 1481, 1463, 1445, 1435, 1394, 1380, 1367, 1332, 1309, 1250, 1238, 1184, 1163, 1154, 1127, 1108, 1051, 904, 884, 858, 841, 807, 791, 746, 740, 687 $\mathrm{cm}^{-1} ;{ }^{1} \mathrm{H}$ NMR (500 MHz, $\left.\mathrm{CDCl}_{3}\right): \delta$ (ppm) 10.56 (br s, $\left.1 \mathrm{H}\right), 7.94$ $(\mathrm{d}, J=7.6 \mathrm{~Hz}, 1 \mathrm{H}), 7.90(\mathrm{dd}, J=8.8,0.9 \mathrm{~Hz}, 1 \mathrm{H}), 7.65-7.70(\mathrm{~m}$, $2 \mathrm{H}), 7.47(\mathrm{dt}, J=8.1,0.9 \mathrm{~Hz}, 1 \mathrm{H}), 7.26(\mathrm{ddd}, J=8.1,7.9,1.0 \mathrm{~Hz}$, 1H), 7.15 (ddd, $J=7.9,7.6,0.9 \mathrm{~Hz}, 1 \mathrm{H}), 2.65$ (s, 3H); ${ }^{13} \mathrm{C} \mathrm{NMR}$ $\left(75.5 \mathrm{MHz}, \mathrm{CDCl}_{3}\right): \delta(\mathrm{ppm})$ 155.6, 152.8, 136.0, 130.1, 129.9, 129.3, 126.5, 125.7, 123.1, 119.5, 119.3, 119.0, 111.7, 111.2, 11.5; HRMS-EI $(\mathrm{m} / \mathrm{z})$ : $[\mathrm{M}]^{+}$calcd for $\mathrm{C}_{15} \mathrm{H}_{11} \mathrm{~N}_{3} \mathrm{~S}, 265.0674$; found, 265.0668 .

\section{Synthesis of $\mathrm{N}$-substituted-indolylbenzothiadiazole derivatives 1d-h}

Typical experimental procedure (1d, Scheme 1). To a stirred suspension of sodium hydride $(60 \%$ mineral oil dispersion, $24 \mathrm{mg}, 0.6 \mathrm{mmol})$, washed with hexane prior to use, in THF (3.0 $\mathrm{mL}$ ) 4-(3-methyl-1 $H$-indol-2-yl)-2,1,3-benzothiadiazole (3, $80 \mathrm{mg}, 0.30 \mathrm{mmol})$ in $\mathrm{THF}(3.0 \mathrm{~mL})$ was added dropwise through a syringe at $0{ }^{\circ} \mathrm{C}$. The reaction mixture was stirred at room temperature for $1 \mathrm{~h}$. To the mixture was added dropwise a solution of ethyl chloroformate $(65 \mathrm{mg}, 0.6 \mathrm{mmol}$ ) in THF (3.0 $\mathrm{mL}$ ) through a syringe. After the reaction mixture was stirred at room temperature for $24 \mathrm{~h}$, water was added to the reaction mixture at $0{ }^{\circ} \mathrm{C}$. The organic layer was separated and the aqueous layer was extracted with dichloromethane three times. 
The combined organic layer was washed with water and brine, and dried over anhydrous $\mathrm{Na}_{2} \mathrm{SO}_{4}$. After removal of the solvent under reduced pressure, crude product was purified with silicagel column chromatography (hexane/diethyl ether $=1: 1$ ) to give ethyl 2-(2,1,3-benzothiadiazol-4-yl)-3-methyl-1 $H$-indole-1carboxylate (1d, $92 \mathrm{mg}, 91 \%)$ as yellow solid.

Ethyl 2-(2,1,3-benzothiadiazol-4-yl)-3-methyl-1 $\mathrm{H}$-indole-1carboxylate (1d). Yellow solid; mp 97-98 ${ }^{\circ} \mathrm{C}$; IR (KBr): $\nu_{\max }$ 3049, 2978, 2930, 2912, 2869, 1733, 1601, 1538, 1479, 1456, 1412, 1379, 1328, 1320, 1302, 1281, 1226, 1198, 1161, 1128, $1117,1025,889,848,830,810,742,704,676 \mathrm{~cm}^{-1} ;{ }^{1} \mathrm{H}$ NMR $(300$ $\left.\mathrm{MHz}, \mathrm{CDCl}_{3}\right): \delta(\mathrm{ppm}) 8.26(\mathrm{dt}, J=8.3,1.0 \mathrm{~Hz}, 1 \mathrm{H}), 8.04(\mathrm{dd}, J=$ 8.7, $0.9 \mathrm{~Hz}, 1 \mathrm{H}), 7.70(\mathrm{dd}, J=8.7,7.0 \mathrm{~Hz}, 1 \mathrm{H}), 7.62-7.55(\mathrm{~m}, 2 \mathrm{H})$, 7.41 (ddd, $J=8.3,7.2,1.3 \mathrm{~Hz}, 1 \mathrm{H}), 7.33$ (ddd, $J=8.2,7.2,1.0 \mathrm{~Hz}$, $1 \mathrm{H}), 4.04-3.87(\mathrm{~m}, 2 \mathrm{H}), 2.21(\mathrm{~s}, 3 \mathrm{H}), 0.68(\mathrm{t}, J=7.0 \mathrm{~Hz}, 3 \mathrm{H}) ;{ }^{13} \mathrm{C}$ NMR (126 MHz, $\left.\mathrm{CDCl}_{3}\right): \delta$ (ppm) 154.82, 154.77, 151.4, 136.4, $130.9,130.5,129.3,129.2$, 127.7, 125.3, 122.9, 121.1, 119.2, 118.6, 115.5, 62.4, 13.3, 9.4; HRMS-ESI $(\mathrm{m} / \mathrm{z}):[\mathrm{M}+\mathrm{H}]^{+}$calcd for $\mathrm{C}_{18} \mathrm{H}_{16} \mathrm{~N}_{3} \mathrm{O}_{2} \mathrm{~S}$, 338.0958; found, 338.0963; crystal data for 1d (CCDC 1523443†): $\mathrm{C}_{18} \mathrm{H}_{15} \mathrm{~N}_{3} \mathrm{O}_{2} \mathrm{~S}, M=337.40$, monoclinic, $a=$

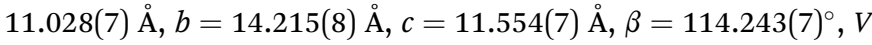
$=1651.5(16) \AA^{3}$, space group $P 2_{1} / c$ (no. 14 ), $Z=4, D_{\mathrm{c}}=1.357 \mathrm{~g}$ $\mathrm{cm}^{-3}, F(000)=704.00, T=223(1) \mathrm{K}, \mu(\mathrm{Mo}-\mathrm{K} \alpha)=2.111 \mathrm{~cm}^{-1}$, 12326 reflections measured, 3762 independent $\left(R_{\text {int }}=0.0526\right)$. The final refinement converged to $R_{1}=0.0724$ for $I>2.0 \sigma(I), \mathrm{w} R_{2}$ $=0.2121$ for all data.

4-(3-Methyl-1-tosyl-1H-indol-2-yl)-2,1,3-benzothiadiazole (1e). According to the typical experimental procedure, the reaction of 3 with $p$-toluenesulfonyl chloride in the presence of sodium hydride was carried out in DMF at room temperature for $16 \mathrm{~h}$ to give 1e in $72 \%$ yield. Yellow solid; mp $177.5-178.3{ }^{\circ} \mathrm{C}$; IR ( $\left.\mathrm{KBr}\right)$ : $\nu_{\max } 3067,2975,2921,1597,1537,1452,1371,1360,1222,1188$, 1173, 1132, 1121, 1089, 1018, 951, 900, 830, 820, 811, 757, 683, $667 \mathrm{~cm}^{-1} ;{ }^{1} \mathrm{H}$ NMR $\left(500 \mathrm{MHz}, \mathrm{CDCl}_{3}\right): \delta(\mathrm{ppm}) 8.30(\mathrm{dt}, J=8.2$, $1.0 \mathrm{~Hz}, 1 \mathrm{H}), 8.11(\mathrm{dd}, J=8.8,1.0 \mathrm{~Hz}, 1 \mathrm{H}), 7.73(\mathrm{dd}, J=8.8,6.9 \mathrm{~Hz}$, $1 \mathrm{H}), 7.61$ (dd, $J=6.9,1.0 \mathrm{~Hz}, 1 \mathrm{H}), 7.50$ (ddd, $J=7.5,1.3,1.0 \mathrm{~Hz}$, $1 \mathrm{H}$ ), 7.40 (ddd, $J=8.2,7.2,1.3 \mathrm{~Hz}, 1 \mathrm{H}$ ), 7.32 (ddd, $J=7.5,7.2$, $1.0 \mathrm{~Hz}, 1 \mathrm{H}), 7.27$ (d, $J=8.2 \mathrm{~Hz}, 2 \mathrm{H}), 6.96$ (d, $J=8.2 \mathrm{~Hz}, 2 \mathrm{H}), 2.26$ (s, 3H), $2.02(\mathrm{~s}, 3 \mathrm{H}) ;{ }^{13} \mathrm{C}$ NMR (126 MHz, $\left.\mathrm{CDCl}_{3}\right): \delta(\mathrm{ppm})$ 154.63, 154.62 , 144.4, 137.4, 135.1, 132.2, 131.5, 131.3, 129.2, 128.8, 126.7, 125.38, 125.35, 123.8, 122.1, 121.5, 119.4, 115.9, 21.5, 9.7; HRMS-ESI $(m / z):[\mathrm{M}+\mathrm{H}]^{+}$calcd for $\mathrm{C}_{22} \mathrm{H}_{18} \mathrm{~N}_{3} \mathrm{O}_{2} \mathrm{~S}_{2}, 420.0835$; found, 420.0844; crystal data for 1e (CCDC 1523444 $\dagger$ ): $\mathrm{C}_{22} \mathrm{H}_{17^{-}}$ $\mathrm{N}_{3} \mathrm{O}_{2} \mathrm{~S}_{2} \cdot \mathrm{CHCl}_{3}, M=538.89$, triclinic, $a=11.305(8) \AA, \quad b=$ $11.319(8) \AA, c=11.788(8) \AA, \alpha=109.674(6)^{\circ}, \beta=98.760(4)^{\circ}, \gamma=$ $115.528(4)^{\circ}, V=1200.7(14) \AA^{3}$, space group $P \overline{1}$ (no. 2$), Z=2, D_{\mathrm{c}}=$ $1.490 \mathrm{~g} \mathrm{~cm}^{-3}, F(000)=552.00, T=223(1) \mathrm{K}, \mu($ Mo-K $\alpha)=5.820$ $\mathrm{cm}^{-1}, 8608$ reflections measured, 5216 independent $\left(R_{\mathrm{int}}=\right.$ $0.0363)$. The final refinement converged to $R_{1}=0.0658$ for $I>$ $2.0 \sigma(I), \mathrm{w} R_{2}=0.1911$ for all data.

2-(2,1,3-Benzothiadiazol-4-yl)-3-methyl-1H-indol-1-yl(phenyl)methanone (1f). According to the typical experimental procedure, the reaction of $\mathbf{3}$ with benzoyl chloride in the presence of sodium hydride was carried out in DMF at room temperature for $16 \mathrm{~h}$ to give $\mathbf{1 f}$ in $69 \%$ yield. Yellow solid; mp $191.2-191.6{ }^{\circ} \mathrm{C}$; IR (KBr): $\nu_{\max } 3052$, 2913, 2858, 1673, 1598, 1598, 1535, 1473, 1453, 1390, 1351, 1331, 1230, 1201, 1152, 1051, 1024, 902, 874, 853,
829, 812, 761, 748, 716, 697, $669 \mathrm{~cm}^{-1} ;{ }^{1} \mathrm{H}$ NMR $(500 \mathrm{MHz}$, $\left.\mathrm{CDCl}_{3}\right): \delta(\mathrm{ppm}) 7.80-7.76(\mathrm{~m}, 1 \mathrm{H}), 7.69-7.64(\mathrm{~m}, 2 \mathrm{H}), 7.54-7.52$ $(\mathrm{m}, 2 \mathrm{H}), 7.44(\mathrm{~d}, J=7.3 \mathrm{~Hz}, 2 \mathrm{H}), 7.34-7.28(\mathrm{~m}, 2 \mathrm{H}), 7.21(\mathrm{t}, J=$ $9.1 \mathrm{~Hz}, 1 \mathrm{H}), 7.05$ (t, $J=7.9 \mathrm{~Hz}, 2 \mathrm{H}), 2.33(\mathrm{~s}, 3 \mathrm{H}) ;{ }^{13} \mathrm{C}$ NMR $(126$ $\left.\mathrm{MHz} \mathrm{CDCl}_{3}\right): \delta$ (ppm) 169.6, 154.6, 153.6, 137.3, 135.1, 131.94, $131.88,130.4$, 130.1, 129.2, 129.0, 127.5, 126.6, 125.1, 122.9, 121.0, 119.3, 118.9, 114.6, 9.7; HRMS-ESI $(\mathrm{m} / \mathrm{z}):[\mathrm{M}+\mathrm{H}]^{+}$calcd for $\mathrm{C}_{22} \mathrm{H}_{16} \mathrm{~N}_{3} \mathrm{OS}$, 370.1009; found, 370.1021; crystal data for $\mathbf{1 f}$ (CCDC 1523445†): $\mathrm{C}_{22} \mathrm{H}_{15} \mathrm{~N}_{3} \mathrm{OS}, M=369.44$, monoclinic, $a=$ 20.828(7) $\mathrm{A}, b=11.825(4) \AA, c=15.926(5) \AA, \beta=111.203(4)^{\circ}, V=$ $3657(2) \AA^{3}$, space group $C 2 / c$ (no. 15$), Z=8, D_{\mathrm{c}}=1.342 \mathrm{~g} \mathrm{~cm}^{-3}$, $F(000)=1536.00, T=223(1) \mathrm{K}, \mu(\mathrm{Mo}-\mathrm{K} \alpha)=1.937 \mathrm{~cm}^{-1}, 13776$ reflections measured, 4172 independent $\left(R_{\text {int }}=0.0591\right)$. The final refinement converged to $R_{1}=0.0843$ for $I>2.0 \sigma(I), \mathrm{w} R_{2}=$ 0.2476 for all data.

2-(2,1,3-Benzothiadiazol-4-yl)-3-methyl-1 $H$-indol-1-yl-2,2-dimethylpropan-1-one (19). According to the typical experimental procedure, the reaction of 3 with pivaloyl chloride in the presence of sodium hydride was carried out in DMF at room temperature for $16 \mathrm{~h}$ to give $1 \mathrm{~g}$ in $66 \%$ yield. Yelloworange solid; mp 135.6-137.2 ${ }^{\circ} \mathrm{C}$; IR (KBr): $\nu_{\max } 3065,2970$, 2927, 2864, 1715, 1475, 1449, 1327, 1299, 1220, 1172, 1126, 908, 856, 841, 823, 810, 776, 756, 750, 638, $619 \mathrm{~cm}^{-1} ;{ }^{1} \mathrm{H}$ NMR $\left(500 \mathrm{MHz}, \mathrm{CDCl}_{3}\right): \delta(\mathrm{ppm}) 8.06(\mathrm{dd}, J=8.9,1.1 \mathrm{~Hz}, 1 \mathrm{H}), 7.71$ $(\mathrm{dd}, J=8.7,6.8 \mathrm{~Hz}, 1 \mathrm{H}), 7.64(\mathrm{dd}, J=7.8,0.9 \mathrm{~Hz}, 1 \mathrm{H}), 7.60$ (dd, $J=6.9,0.9 \mathrm{~Hz}, 1 \mathrm{H}), 7.53(\mathrm{dd}, J=8.2,0.9 \mathrm{~Hz}, 1 \mathrm{H}), 7.33(\mathrm{ddd}, J=$ 8.2, 7.8, $0.9 \mathrm{~Hz}, 1 \mathrm{H}), 7.25(\mathrm{td}, J=8.2,0.9 \mathrm{~Hz}, 1 \mathrm{H}), 2.28(\mathrm{~s}, 3 \mathrm{H})$, 0.96 (s, 9H); ${ }^{13} \mathrm{C} \mathrm{NMR}\left(126 \mathrm{MHz}, \mathrm{CDCl}_{3}\right): \delta$ (ppm) 184.9, 155.1, $153.5,136.4,131.1,130.5,129.4,129.3,127.1,124.3,121.4$, 121.3, 119.4, 116.6, 112.3, 43.9, 27.9, 10.0; HRMS-ESI $(\mathrm{m} / \mathrm{z})$ : [M $+\mathrm{H}]^{+}$calcd for $\mathrm{C}_{20} \mathrm{H}_{20} \mathrm{~N}_{3} \mathrm{OS}, 350.1322$; found, 350.1332. Crystal data for $1 \mathrm{~g}$ (CCDC 1523446†): $\mathrm{C}_{20} \mathrm{H}_{19} \mathrm{~N}_{3} \mathrm{OS}, M=349.45$, monoclinic, $a=12.119(5) \AA, b=13.780(5) \AA, c=21.310(8) \AA$, $\beta=98.941(7)^{\circ}, V=3516(2) \AA^{3}$, space group $P 2_{1} / n$ (no. 14$), Z=$ $8, D_{\mathrm{c}}=1.320 \mathrm{~g} \mathrm{~cm}^{-3}, F(000)=1472.00, T=223(1) \mathrm{K}, \mu(\mathrm{Mo}-\mathrm{K} \alpha)$ $=1.968 \mathrm{~cm}^{-1}, 27090$ reflections measured, 8018 independent $\left(R_{\text {int }}=0.0360\right)$. The final refinement converged to $R_{1}=0.0506$ for $I>2.0 \sigma(I), \mathrm{w} R_{2}=0.1268$ for all data.

4-(1,3-Dimethyl-1H-indol-2-yl)-2,1,3-benzothiadiazole (1h). According to the typical experimental procedure, the reaction of 3 with methyl iodide in the presence of sodium hydride was carried out in THF at room temperature for $16 \mathrm{~h}$ to give $\mathbf{1 h}$ in 94\% yield. Orange solid; mp $140.2-140.8^{\circ} \mathrm{C}$; IR (KBr): $\nu_{\max } 3044$, 2921, 2904, 1592, 1558, 1470, 1362, 1329, 1312, 1268, 1244, 1174, 1158, 1128, 1007, 951, 896, 855, 828, 758, $741 \mathrm{~cm}^{-1} ;{ }^{1} \mathrm{H}$ NMR $\left(500 \mathrm{MHz}, \mathrm{CDCl}_{3}\right): \delta(\mathrm{ppm}) 8.10(\mathrm{dd}, J=8.8,1.0 \mathrm{~Hz}, 1 \mathrm{H})$, $7.74(\mathrm{dd}, J=8.8,6.8 \mathrm{~Hz}, 1 \mathrm{H}), 7.65$ (d, $J=7.9 \mathrm{~Hz}, 1 \mathrm{H}), 7.61$ (dd, $J$ $=6.8,1.0 \mathrm{~Hz}, 1 \mathrm{H}), 7.38(\mathrm{~d}, J=8.2 \mathrm{~Hz}, 1 \mathrm{H}), 7.30(\mathrm{dd}, J=7.9$, $7.3 \mathrm{~Hz}, 1 \mathrm{H}), 7.17$ (dd, $J=8.2,7.3 \mathrm{~Hz}, 1 \mathrm{H}), 3.57$ (s, 3H), 2.27 (s, $3 \mathrm{H}) ;{ }^{13} \mathrm{C} \mathrm{NMR}\left(126 \mathrm{MHz}, \mathrm{CDCl}_{3}\right): \delta$ (ppm) 155.1, 154.4, 137.7, 133.2, 131.7, 129.2, 128.4, 125.9, 122.3, 121.5, 119.23, 119.16, 110.9, 109.4, 31.5, 9.6; anal. calcd for $\mathrm{C}_{16} \mathrm{H}_{13} \mathrm{~N}_{3} \mathrm{~S}$ : C, 68.79; $\mathrm{H}$, 4.69; N, 15.04; S, 11.48. Found: C, 68.40; H, 4.76; N, 14.96; S, 11.48. Crystal data for 1 h (CCDC $1523447 \dagger$ ): $\mathrm{C}_{16} \mathrm{H}_{13} \mathrm{~N}_{3} \mathrm{~S}, M=$ 279.36, triclinic, $a=8.367(3) \AA, b=8.840(3) \AA, c=10.153(3) \AA$, $\alpha=80.099(13)^{\circ}, \beta=67.010(11)^{\circ}, \gamma=82.285(14)^{\circ}, V=679.2(4)$ $\AA^{3}$, space group $P \overline{1}$ (no. 2 ), $Z=2, D_{\mathrm{c}}=1.366 \mathrm{~g} \mathrm{~cm}^{-3}, F(000)=$ 
292.00, $T=223(1) \mathrm{K}, \mu(\mathrm{Mo}-\mathrm{K} \alpha)=2.305 \mathrm{~cm}^{-1}, 4962$ reflections measured, 2968 independent $\left(R_{\text {int }}=0.0181\right)$. The final refinement converged to $R_{1}=0.0610$ for $I>2.0 \sigma(I), \mathrm{w} R_{2}=0.1786$ for all data.

\section{Theoretical calculations}

The theoretical calculations were performed using Gaussian 09 program. $^{22}$ Molecular geometry of $\mathbf{1 b}$ was optimized using density functional theory (DFT) calculations at the CAM-B3LYP/ 6-31G(d) level of theory. The single-crystal X-ray structure of $\mathbf{1 b}$ was used as a starting point. The long-range corrected hybrid functional CAM-B3LYP was used as CAM-B3LYP often provides better results in time-dependent density functional theory (TDDFT) calculations than conventional B3LYP. ${ }^{23}$ The HOMO and LUMO energy levels of $\mathbf{1 b}$ are $-6.90 \mathrm{eV}$ and $-1.00 \mathrm{eV}$, respectively. The lowest 6 singlet-singlet transitions of $\mathbf{1 b}$ were computed by the TD-DFT calculation at the CAM-B3LYP/6$31 \mathrm{G}(\mathrm{d})$ level of theory. The calculated first excited state, which consists of the transition from HOMO to LUMO (0.669), is $336 \mathrm{~nm}(3.69 \mathrm{eV})$ with oscillator strength of 0.187 . The theoretical calculations of other compounds $\mathbf{1 c - h}$ were also carried out as described for $\mathbf{1 b}$ (Table $\mathrm{S} 1 \dagger$ ).

\section{Acknowledgements}

This work was partly supported by the Futaba Electronic Memorial Foundation. The authors are grateful to Mr Shinji Ishihara (Instrumental Analysis Center, Yokohama National University) for EI- and ESI-HRMS analyses and elemental analyses.

\section{References}

1 For recent reviews, see: (a) Y. Sagara, S. Yamane, M. Mitani, C. Weder and T. Kato, Adv. Mater., 2016, 28, 1073; (b) Z. Ma, Z. Wang, M. Teng, Z. Xu and X. Jia, ChemPhysChem, 2015, 16, 1811.

2 For a review, see: M. Shimizu and T. Hiyama, Chem.-Asian J., 2010, 5, 1516.

3 For a review, see: J. Mei, N. L. C. Leung, R. T. K. Kwok, J. W. Y. Lam and B. Z. Tang, Chem. Rev., 2015, 115, 11718.

4 For recent examples based on tetraphenylethenes, see: $(a)$ Z. Zhuang, P. Shen, S. Ding, W. Luo, B. He, H. Nie, B. Wang, T. Huang, R. Hu, A. Qin, Z. Zhao and B. Z. Tang, Chem. Commun., 2016, 52, 10842; (b) X. Fang, Y.-M. Zhang, K. Chang, Z. Liu, X. Su, H. Chen, S. X.-A. Zhang, Y. Liu and C. Wu, Chem. Mater., 2016, 28, 6628; (c) Z. Ma, Z. Wang, X. Meng, Z. Ma, Z. Xu, Y. Ma and X. Jia, Angew. Chem., Int. Ed., 2016, 55, 519; (d) Z. He, L. Zhang, J. Mei, T. Zhang, J. W. Y. Lam, Z. Shuai, Y. Q. Dong and B. Z. Tang, Chem. Mater., 2015, 27, 6601; (e) B. Xu, J. He, Y. Mu, Q. Zhu, S. Wu, Y. Wang, Y. Zhang, C. Jin, C. Lo, Z. Chi, A. Lien, S. Liu and J. Xu, Chem. Sci., 2015, 6, 3236.

5 For recent examples based on distyrylarene derivatives, see:

(a) H.-J. Kim, D. R. Whang, J. Gierschner, C. H. Lee and S. Y. Park, Angew. Chem., Int. Ed., 2015, 54, 4330; (b)
Y. Xiong, X. Yan, Y. Ma, Y. Li, G. Yin and L. Chen, Chem. Commun., 2015, 51, 3403; (c) G. Fan and D. Yan, Sci. Rep., 2014, 4, 4933; (d) S. Yagai, S. Okamura, Y. Nakano, M. Yamauchi, K. Kishikawa, T. Karatsu, A. Kitamura, A. Ueno, D. Kuzuhara, H. Yamada, T. Seki and H. Ito, Nat. Commun., 2014, 5, 4013; (e) Y. Dong, B. Xu, J. Zhang, X. Tan, L. Wang, J. Chen, H. Lv, S. Wen, B. Li, L. Ye, B. Zou and W. Tian, Angew. Chem., Int. Ed., 2012, 51, 10782.

6 For recent examples based on triarylamines, see: (a) J. Zhang, Z. Chen, L. Yang, F. Hu, G.-A. Yu, J. Yin and S.-H. Liu, Dyes Pigm., 2017, 136, 168; (b) Y. Chen, Y. Ling, L. Ding, C. Xiang and G. Zhou, J. Mater. Chem. C, 2016, 4, 8496; (c) Z.-F. Chang, L.-M. Jing, Y.-Y. Liu, J.-J. Liu, Y.-C. Ye, Y. S. Zhao, S.-C. Yuan and J.-L. Wang, J. Mater. Chem. C, 2016, 4, 8407; (d) Y. Lei, Y. Liu, Y. Guo, J. Chen, X. Huang, W. Gao, L. Qian, H. Wu, M. Liu and Y. Cheng, J. Phys. Chem. C, 2015, 119, 23138; (e) P. S. Hariharan, N. S. Venkataramanan, D. Moon and S. P. Anthony, J. Phys. Chem. C, 2015, 119, 9460.

7 For recent examples based on boron difluorides, see: $(a)$ M. Yamaguchi, S. Ito, A. Hirose, K. Tanaka and Y. Chujo, J. Mater. Chem. C, 2016, 4, 5314; (b) S. Wang, R. Tan, Y. Li, Q. Li and S. Xiao, Dyes Pigm., 2016, 132, 342; (c) W. A. Morris, M. Kolpaczynska and C. L. Fraser, J. Phys. Chem. C, 2016, 120, 22539; (d) T. Butler, W. A. Morris, J. Samonina-Kosicka and C. L. Fraser, ACS Appl. Mater. Interfaces, 2016, 8, 1242; (e) Z. Zhang, Z. Wu, J. Sun, B. Yao, G. Zhang, P. Xue and R. Lu, J. Mater. Chem. C, 2015, 3, 4921. 8 For recent examples based on other fluorophores, see: $(a)$ S. Ito, T. Yamada and M. Asami, ChemPlusChem, 2016, 81, 1272; (b) Y. Sagara, Y. C. Simon, N. Tamaoki and C. Weder, Chem. Commun., 2016, 52, 5694; (c) B. Xu, Y. Mu, Z. Mao, Z. Xie, H. Wu, Y. Zhang, C. Jin, Z. Chi, S. Liu, J. Xu, Y.-C. Wu, P.-Y. Lu, A. Lien and M. R. Bryce, Chem. Sci., 2016, 7, 2201; (d) Y. Matsunaga and J.-S. Yang, Angew. Chem., Int. Ed., 2015, 54, 7985; (e) Z. Xie, C. Chen, S. Xu, J. Li, Y. Zhang, S. Liu, J. Xu and Z. Chi, Angew. Chem., Int. Ed., 2015, 54, 7181; $(f)$ M. Tanioka, S. Kamino, A. Muranaka, Y. Ooyama, H. Ota, Y. Shirasaki, J. Horigome, M. Ueda, M. Uchiyama, D. Sawada and S. Enomoto, J. Am. Chem. Soc., 2015, 137, 6436; (g) Y. Jiang, D. Gindre, M. Allain, P. Liu, C. Cabanetos and J. Roncali, Adv. Mater., 2015, 27, 4285; (h) R. Li, S. Xiao, Y. Li, Q. Lin, R. Zhang, J. Zhao, C. Yang, K. Zou, D. Li and T. Yi, Chem. Sci., 2014, 5, 3922; (i) K. Nagura, S. Saito, H. Yusa, H. Yamawaki, H. Fujihisa, H. Sato, Y. Shimoikeda and S. Yamaguchi, J. Am. Chem. Soc., 2013, 135, 10322.

9 Mechanochromic luminescence has also been observed for some liquid-crystalline compounds and metal complexes. For recent examples, see: (a) B. Huitorel, Q. Benito, A. Fargues, A. Garcia, T. Gacoin, J.-P. Boilot, S. Perruchas and F. Camerel, Chem. Mater., 2016, 28, 8190; (b) O. Toma, M. Allain, F. Meinardi, A. Forni, C. Botta and N. Mercier, Angew. Chem., Int. Ed., 2016, 55, 7998; (c) T. Seki, Y. Takamatsu and H. Ito, J. Am. Chem. Soc., 2016, 138, 6252; (d) M. Mitani, S. Ogata, S. Yamane, M. Yoshio, M. Hasegawa and T. Kato, J. Mater. Chem. C, 2016, 4, 2752; 
(e) S. Yagai, T. Seki, H. Aonuma, K. Kawaguchi, T. Karatsu, T. Okura, A. Sakon, H. Uekusa and H. Ito, Chem. Mater., 2016, 28, 234; (f) Q. Benito, X. F. Le Goff, S. Maron, A. Fargues, A. Garcia, C. Martineau, F. Taulelle, S. Kahlal, T. Gacoin, J.-P. Boilot and S. Perruchas, J. Am. Chem. Soc., 2014, 136, 11311; (g) M. Krikorian, S. Liu and T. M. Swager, J. Am. Chem. Soc., 2014, 136, 2952.

10 For self-recovering mechanochromic organic luminophores, see: (a) H. Wu, C. Hang, X. Li, L. Yin, M. Zhu, J. Zhang, Y. Zhou, H. Ågren, Q. Zhang and L. Zhu, Chem. Commun., 2017, 53, 2661; (b) D. Tu, P. Leong, Z. Li, R. Hu, C. Shi, K. Y. Zhang, H. Yan and Q. Zhao, Chem. Commun., 2016, 52, 12494; (c) K. C. Naeem, A. Subhakumari, S. Varughese and V. C. Nair, J. Mater. Chem. C, 2015, 3, 10225; (d) Y. Lin, G. Chen, L. Zhao, W. Z. Yuan, Y. Zhang and B. Z. Tang, J. Mater. Chem. C, 2015, 3, 112; (e) L. Bu, M. Sun, D. Zhang, W. Liu, Y. Wang, M. Zheng, S. Xue and W. Yang, J. Mater. Chem. C, 2013, 1, 2028; (f) K. Mizuguchi, H. Kageyama and H. Nakano, Mater. Lett., 2011, 65, 2658; $(g)$ G. Zhang, J. Lu, M. Sabat and C. L. Fraser, J. Am. Chem. Soc., 2010, 132, 2160. See also: ref. $4 b, 6 e$ and $9 d$.

11 S. Ito, T. Yamada, T. Taguchi, Y. Yamaguchi and M. Asami, Chem.-Asian J., 2016, 11, 1963.

12 Single crystals of $1 \mathrm{e}$ contained chloroform molecules. The calculated powder diffraction patterns for these single crystals were thus different from the results of the PXRD analysis on the powdered sample.

13 T. Yanai, D. P. Tew and N. C. Handy, Chem. Phys. Lett., 2004, 393, 51.

14 P. Suppan, J. Photochem. Photobiol., A, 1990, 50, 293.

15 The emission maximum of a tetraphenylethylene derivative after grinding was different from the emission maximum of its molten form; see: X. Zhou, H. Li, Z. Chi, X. Zhang, J. Zhang, B. Xu, Y. Zhang, S. Liu and J. Xu, New J. Chem., 2012, 36, 685.

16 The emission maxima of two diphenyldibenzofulvene derivatives after grinding were almost identical to those of their molten form, although the emission intensity decreased considerably; see: X. Luo, J. Li, C. Li, L. Heng, Y. Q. Dong, Z. Liu, Z. Bo and B. Z. Tang, Adv. Mater., 2011, 23, 3261 .

17 The melting point of $\mathbf{1 b}\left(128.0-128.6^{\circ} \mathrm{C}\right)$ was below the decomposition temperature of the Boc group $\left(>140^{\circ} \mathrm{C}\right)$.

18 G. Özüduru, T. Schubach and M. M. K. Boysen, Org. Lett., 2012, 14, 4990.

19 R. D. Clark and A. Jahangir, Lateral Lithiation Reactions Promoted by Heteroaromatic Substituents; Organic Reactions, Wiley, New York, 1995, vol. 47, pp. 1-314.

20 Y.-M. Su, Y. Hou, F. Yin, Y.-M. Xu, Y. Li, X. Zheng and X.-S. Wang, Org. Lett., 2014, 16, 2958.

21 J. Guo, S. Wang, N. Dai, Y. N. Teo and E. T. Kool, Proc. Natl. Acad. Sci. U. S. A., 2011, 108, 3493.

22 M. J. Frisch, G. W. Trucks, H. B. Schlegel, G. E. Scuseria, M. A. Robb, J. R. Cheeseman, G. Scalmani, V. Barone, B. Mennucci, G. A. Petersson, H. Nakatsuji, M. Caricato, X. Li, H. P. Hratchian, A. F. Izmaylov, J. Bloino, G. Zheng, J. L. Sonnenberg, M. Hada, M. Ehara, K. Toyota, R. Fukuda, J. Hasegawa, M. Ishida, T. Nakajima, Y. Honda, O. Kitao, H. Nakai, T. Vreven, J. A. Montgomery Jr, J. E. Peralta, F. Ogliaro, M. Bearpark, J. J. Heyd, E. Brothers, K. N. Kudin, V. N. Staroverov, R. Kobayashi, J. Normand, K. Raghavachari, A. Rendell, J. C. Burant, S. S. Iyengar, J. Tomasi, M. Cossi, N. Rega, J. M. Millam, M. Klene, J. E. Knox, J. B. Cross, V. Bakken, C. Adamo, J. Jaramillo, R. Gomperts, R. E. Stratmann, O. Yazyev, A. J. Austin, R. Cammi, C. Pomelli, J. W. Ochterski, R. L. Martin, K. Morokuma, V. G. Zakrzewski, G. A. Voth, P. Salvador, J. J. Dannenberg, S. Dapprich, A. D. Daniels, Ö. Farkas, J. B. Foresman, J. V. Ortiz, J. Cioslowski and D. J. Fox, Gaussian, Inc., Wallingford CT, 2009.

23 D. Jacquemin, E. A. Perpète, G. E. Scuseria, I. Ciofini and

C. Adamo, J. Chem. Theory Comput., 2008, 4, 123. 